\title{
Real-time forecasting of flows
}

\author{
J. E. Stoyko \& A. I. Ramírez \\ Centro del Agua para Latina América y el Caribe, \\ Tecnológico de Monterrey, Mexico
}

\begin{abstract}
The impacts brought on by flash flooding are widespread, posing a threat to property and human life. Flood warning systems are implemented in many countries to alert affected populations of potential hazards. However, many of these systems do not generate a forecast with a sufficient amount of lead-time to alert the affected populations. Therefore, stream discharge forecasts in real-time are necessary. Real-time stream discharge forecasts rely on the use of weather forecasts, predicting precipitation in a given area. Products used for weather forecasts include weather radar, satellite, and weather models. Integrating these products with a rainfall-runoff modelling technique, such as an adapted version of the unit hydrograph at a given point in a stream, allows for a stream discharge forecast before the occurrence of a precipitation event. A base unit hydrograph for the duration in excess of 10 minutes can be computed with the use of historic precipitation and stream flow data. It can then be applied to areas that do not have available data in real-time. The proposed model for the unit hydrograph for the duration in excess was computed using data from Southern Mexico, specifically from the states of Chiapas and Tabasco. It allows for the forecasting of stream flows after a first impulse of precipitation has fallen over the watershed, using a typical daily precipitation distribution. The area has witnessed major flood events; therefore the application of such a model would be of great use to prepare for potential flooding as well as the evacuation of communities located in the flood plain. The methodology developed in this model can be applied to other watersheds, where real-time data availability is limited.
\end{abstract}

Keywords: hydrological modelling, flow forecasting, real-time, stream discharge. 


\section{Introduction}

Stream flow forecasting is very important, due to property damage and the loss of life flooding may cause. Downstream residential areas as well as agricultural land and reservoirs are susceptible to flood damage. The urbanisation of cities and their encroachment on rural landscapes often leads to deforestation, increasing the severity and destruction flooding may cause (Baltas [1]). In the United States, 100 people lose their lives due to flooding annually, with damage averaging more than USD \$2 billion (Sharif et al. [2]). Climate change projections indicate that there will be an increase in the intensity of rainfall in some parts of the world, increasing the risk of flooding (Hapuarachchi et al. [3]). It is necessary to estimate the risk and implement effective mitigation measures to prevent such disasters.

Weather forecasting of precipitation alone is not sufficient to mitigate a possible disaster, as stream flows may cause more problems than the actual rainfall. An example includes the fact that many roads traverse flood plains that are susceptible to flooding, where many flash flood victims are unsuspecting motorists (Versini [4]) who drive straight into the stream flows. With a real-time flow forecast, it would not only be possible to coordinate rescue missions for people trapped in the water flows, but to prevent people from becoming victims in the first place. A flow forecast in real-time can provide the appropriate authorities with the means of notifying people, their evacuation, as well as closing down affected roadways before the arrival of flood waters. Therefore, a flood forecasting system with high spatial resolution and useful lead-time is necessary (Hapuarachchi et al. [3]).

In many parts of the world, precipitation and stream flow data availability in real-time is non-existent, due to the high costs associated with digital gauges and data transmission. However, historical stream flow and precipitation data are widely available (Ghile et al. [5]), where this data can be implemented into a model. Rain gauges are some of the most precise and richest sources of data for rainfall information (Ghile et al. [5]), as estimations from radar networks may be sparse in time and space, or nonexistent (Behrangi et al. [6]), and satellite-based precipitation estimates are not sufficiently advanced to be used alone in operational mode (Versini [4]). The model proposed is to be simple and easily applied to different watersheds where real-time data is lacking, as well as to be linked with precipitation forecasts of the said area. This would allow for the forecasting of potential flooding in real-time, as well as allow time for flood preparation and evacuation.

\section{Methods}

The model is to be developed, applied and tested in a region where flooding frequently occurs, as to get the largest benefit from its application. With its application to a part of the Grijalva River Watershed in Southern Mexico, which spans the states of Tabasco and Chiapas, flood forecasting in the area would be greatly improved. This area receives on average, between 1000 and $4700 \mathrm{~mm}$ of 
precipitation per year, depending on the altitude (Velasco et al. [7]). With this large amount of precipitation and available precipitation and stream flow data, the Grijalva River Watershed is suitable for the compilation of the proposed model. The objective is to compute a modified version of the most common unit hydrograph with a $\Delta t$ of 10 minutes at different points in the subwatersheds analysed, as to evaluate and apply it to future precipitation events, thus enabling better flood forecasting in the area.

\subsection{Subwatersheds selected}

The subwatersheds selected for the purpose of the study have important stream flows and are located upstream from the capital of Tabasco, Villahermosa, which has witnessed many flood events in past years. The subwatersheds included are the following: De la Sierra, Tlacotalpa, Almendro, Plátanos, and Chacté. Figure 1 shows a map of the study area, indicating the location of the subwatersheds selected.

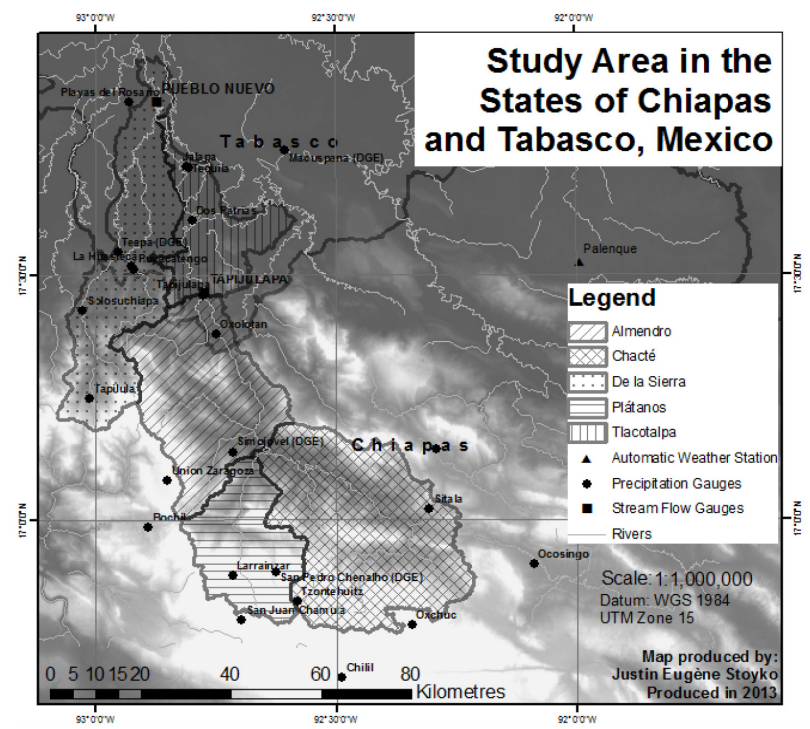

Figure 1: Subwatersheds included in the study, located in the states of Tabasco and Chiapas in Southern Mexico.

\subsection{Data availability \& limitations}

The historic data needed for the purpose of this study were readily available from various sources. Stream gauge data were provided by the National Water Commission of Mexico (CONAGUA), which publishes the information in a database called Banco Nacional de Datos de Aguas Superficiales (BANDAS). Data from the Automatic Weather Stations (EMAs, for the Spanish acronym for Estación Meteorológica Automática), as well as daily precipitation data (from 
conventional climatological stations), were provided by the National Weather Service of Mexico (Servicio Meteorológico Nacional), a division of the CONAGUA. Digital maps of the area were provided by the National Institute of Statistics and Geography of Mexico (INEGI). They enable a visual view of the study area, the ability to delineate the watersheds and calculate their area, as well as the longitude and slope of the principal channel, while using them in conjunction with a Geographic Information System. All of the above mentioned databases and digital maps were free of charge when the study was completed and readily available either online or after asking for the required information.

The data used to build the model were selected from a span of 4 years, from 2003 through to 2006. Data availability was the limiting factor when selecting the time frame for the study. Stream flow data is limited up until the end of 2006, where following years are not yet published. As well, data were required from the nearby Automatic Weather Station (EMA) in Palenque, Chiapas, as to get the time distribution of the daily precipitation from the climatological stations. The Automatic Weather Station in Palenque was installed at the end of 2002, limiting the start of the study's time frame to 2003.

\subsection{Data preparation}

Before conducting any analysis, the raw data was prepared. Stream flow and precipitation gauges were selected in time and space for the purpose of the study. To determine which gauges fall within the delineated study area, a GIS software package was used to plot their location. Their coordinates were extracted from the databases where the data are stored. Once it was determined which stream and precipitation gauges would be used in the analysis, their data were extracted from their respective databases for the years 2003 through 2006.

\subsubsection{Stream flow data preparation}

The next step with regards to the preparation component of the study was to find significant stream flow events that have a smooth curvature at the selected stream discharge gauges (Tapijulapa and Pueblo Nuevo). Once the different stream flow events were selected and exported from the database, the missing data were interpolated in a spreadsheet.

\subsubsection{Precipitation data preparation}

With regards to the preparation of precipitation data, it is necessary to determine which precipitation gauges are associated with the stream discharge gauges analysed. When a precipitation event occurs over a watershed, the rainfall pattern and distribution will vary depending on the location within the watershed. As well, it is necessary to consider that precipitation that has fallen further away will take more time to arrive at the exit point of watershed than precipitation occurring in the immediate area. Thiessen Polygons were used to determine the weight of each conventional climatological station as well as which ones to select.

Once the precipitation gauges for a specific stream gauge were selected using the method explained above, their data were exported for the days related to the 
stream flow events found previously. The Kirpich method was used to estimate the time required for runoff to travel from the most distant point of the watershed, to its outlet. This enables the association of the precipitation and stream flow data related to an event. The following eqn (1) describes the Kirpich method (in hours), where $t_{c}$ is the concentration time (Sharifi and Hosseini [8]).

$$
t_{c}=0.0003245 L^{0.77} S^{-0.385}
$$

As seen in eqn (1), the variable $L$ represents the longest flow path in the watershed (in metres) and $S$ the slope. However, what is needed is the delay for which the water will take to reach the outlet of the watershed $\left(t_{r}\right)$, as described in eqn (2) (UNER [9]).

$$
t_{r}=0.6 t_{c}
$$

With eqn (2), it was possible to determine the approximate maximum delay incurred for precipitation over an area, to reach the watershed's outlet. This allows for the classification of the precipitation data related to the stream flow events extracted previously.

\subsubsection{Automatic weather station data preparation}

The Automatic Weather Station (EMA) at Palenque, Chiapas is located near the subwatersheds that comprise the study area, in an area that has similar topography. Therefore, the precipitation distribution incurred at this weather station is assumed to be similar to that found over the study area. This automatic weather station provides precipitation data for every period of 10 minutes. As the goal is to find the typical daily distribution to then interpolate it over the precipitation data from the conventional climatological stations (in which only daily accumulated precipitation is available), it was necessary to start by extracting data. Firstly, precipitation events amounting to more than $10 \mathrm{~mm}$ per day were extracted from the database. As the daily precipitation gauge data are recorded at 8:00 $\mathrm{AM}$, the time frame for the precipitation events was set from 8:10 AM to 8:00 AM the following day. This was done for the course of the study period.

\subsection{Analysis methods}

Many steps were included in the data analysis. It was necessary to determine the direct runoff from the stream flow events identified earlier and the effective precipitation related to these same events. However, the first step would be to find the typical daily distribution, using the data from the automatic weather station.

\subsubsection{Automatic weather station data analysis}

After having prepared the data for the automatic weather station, the objective was to compute an accumulated precipitation graph in percent total. This enabled the visualisation of the accumulated precipitation curves during a 24-hour period, 
allowing for the most common rain patterns to be determined for a given year. With the calculation of the percent of daily rainfall, it was possible to accumulate the precipitation as to get the distribution of precipitation during the course of a 24-hour period, from 0 to $100 \%$.

Afterwards, the curves for every precipitation event were aligned, where the curves with odd patterns were manually deleted. In general, about 30-40 curves were kept for each year of data analysed. When complete, the precipitation curves for a particular year were averaged as to obtain one common curve. This final precipitation curvature represents the typical precipitation distribution for the year analysed. This precipitation distribution curve was then applied to the total daily precipitation from the conventional climatological stations found in the subwatersheds of the study area.

\subsubsection{Stream flow data analysis}

The analysis of stream flow data includes the removal of the base flow from the flow data being analysed for each stream flow event identified. To do this, it was necessary to find the point in the original hydrographs that show the total stream flows $\left(Q_{T}\right)$, where the volume of base runoff $\left(V_{B}\right)$ was separated from the volume of direct runoff $\left(V_{D}\right)$. In fig. 2 , it is possible to visualise the procedure that must be done to remove the base flow from the flow data analysed. The first graph (left-hand side) represents the total stream flow $\left(Q_{T}\right)$ at the given gauge. The graph on the right-hand side shows the direct flow $\left(Q_{D}\right)$.

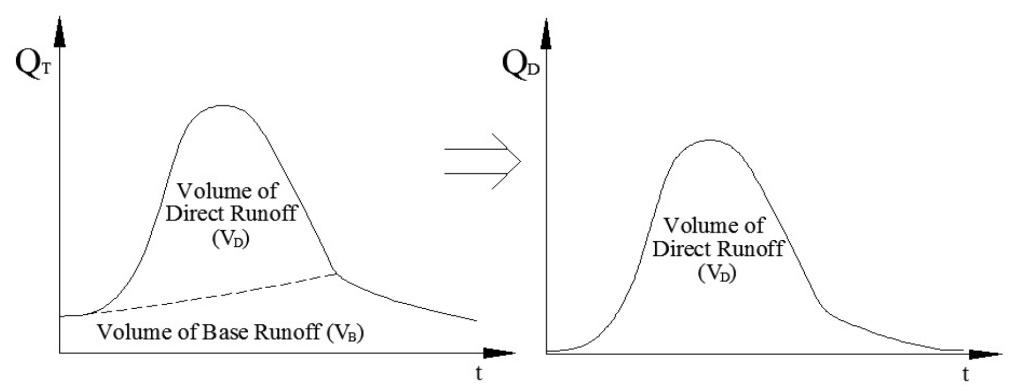

Figure 2: $\quad$ Total $\left(Q_{T}\right)$ and $\operatorname{direct}\left(Q_{D}\right)$ stream flows in $\mathrm{m}^{3} / \mathrm{s}$.

Once the direct stream flow hydrographs $\left(Q_{D}\right)$ were computed, the volume of the direct runoff $\left(V_{D}\right)$ was calculated, which is the area below the curve of the hydrograph. This was done by taking the sum of all the data points related to the direct stream flow and multiplying the total by 3600 seconds, the number of seconds per hour, leaving us with the volume in $\mathrm{m}^{3}$. These values for direct runoff $\left(V_{D}\right)$ calculated for each stream flow event, ready for their input to calculate the effective precipitation $\left(P_{e}\right)$ (discussed in section 2.4.3).

\subsubsection{Precipitation data analysis}

For every precipitation event analysed, the daily precipitation values were interpolated onto the curve of the most common daily precipitation pattern, as 
discussed previously. Multiplying the daily precipitation values by the percent curvature for every 10 minutes during the 24-hour period analysed, results in daily-accumulated precipitation values for every 10 minutes. As the total precipitation $\left(P_{t}\right)$ values for every 10 minutes are needed, every accumulated precipitation value was subtracted by its previous value, as depicted in eqn (3) for total precipitation $\left(P_{t}\right)$.



With the total precipitation $\left(P_{t}\right)$ calculated, it was possible to calculate the average precipitation in the study area for a given precipitation event. Using Thiessen Polygons to represent the area covered by each Climatological Weather Station, it was possible to determine their weight for the purpose of averaging the precipitation that had fallen over the studied watershed. To do this, the precipitation data points from a conventional climatological station $\left(P_{t}\right)$ were multiplied by the area covered by the Thiessen Polygons representing the Climatological Weather Station in question $\left(A_{i}\right)$ over the total area of the watershed $\left(A_{t}\right)$. This procedure was done for all conventional climatological stations included for a precipitation event, where their data points were summed together to get the average precipitation for a particular event. This procedure is represented in the following, eqn (4).

$$
\text { Average Precipitation }=\Sigma\left[P_{t} *\left(A_{i} / A_{t}\right)\right]
$$

After having calculated the average total precipitation, it was then possible to calculate the effective precipitation $\left(P_{e}\right)$. This was done by first using the stream flow data associated to the precipitation event analysed, dividing the total volume of direct stream flow $\left(V_{D}\right)$ by the total watershed area $\left(A_{t}\right.$ in $\left.\mathrm{m}^{3}\right)$, as shown by eqn (5).

$$
\begin{gathered}
P_{e}=V_{D} / A_{t} \\
P_{e}=\Sigma h
\end{gathered}
$$

Once the quantity of effective precipitation $\left(P_{e}\right)$ was calculated using the equation above, the base precipitation was subtracted from the average total precipitation. The hyetographs for total and effective precipitation in fig. 3, visually show the process that was undertaken, where the height of the bars represented by $h$ was calculated using eqn (6), where $h$ is the excess of precipitation over time. Once the values for effective precipitation $\left(P_{e}\right)$ for the different precipitation events were calculated, they were exported to separate archives, ready for their input into the model. 


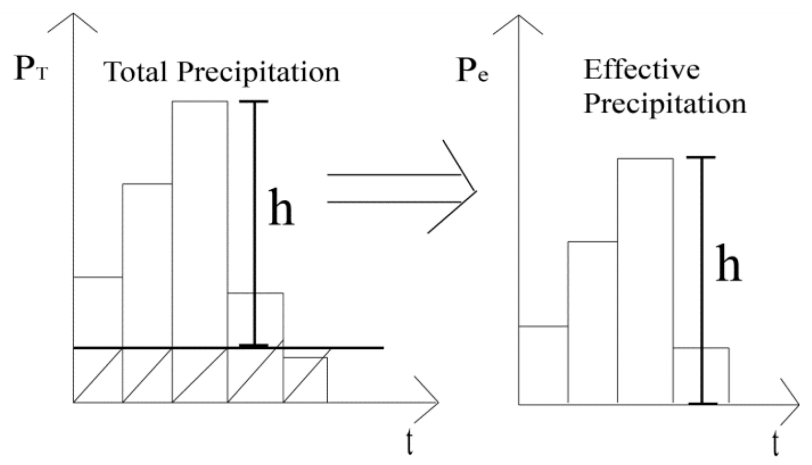

Figure 3: Hyetographs showing total $\left(P_{t}\right)$ and effective $\left(P_{e}\right)$ precipitation.

\subsubsection{Computing the instant unit hydrograph for the duration in excess}

With effective precipitation $\left(P_{e}\right)$ and direct stream flows $\left(Q_{D}\right)$ for a precipitation event, the instant unit hydrograph for the duration in excess was computed using a matrix. This matrix is based on literature by Aparicio-Mijares [10], where the following in eqn (7) is suggested.

$$
P^{T} P\{U\}=P^{T}\{Q\}
$$

Eqn (7) allows the instant unit hydrograph for the duration in excess $\{U\}$ to be solved, where $P$ is the effective precipitation $\left(P_{e}\right)$ and $Q$ is the direct stream flow $\left(Q_{D}\right)$. It is important to note that the direct stream flow hydrographs $\left(Q_{D}\right)$ have data available hourly. Since the precipitation data was computed on a 10-minute time scale, it was necessary to linearly interpolate the data points of the direct runoff as to have data every 10 minutes.

As $\{U\}$ is in $\mathrm{m}^{3} / \mathrm{s} / \mathrm{mm}$, it enables the modelling of stream flows in the given watershed for a determined quantity of precipitation. Averaging the instant unit hydrographs for the duration in excess from the different precipitation events, allows for the most common instant unit hydrograph for the duration in excess to be solved.

\subsubsection{Verifying the instant unit hydrograph for the duration in excess}

After the instant unit hydrographs for the duration in excess were computed for the different precipitation events using the methods described previously, it was important to review the resulting data before any conclusions could be made. First of all, it was necessary to check if the resulting instant unit hydrographs for the duration in excess correlate with the area of the watershed in question. To do this, the volume of each instant unit hydrographs for the duration in excess was summed, as to get its total volume. As the units are in $\mathrm{m}^{3} / \mathrm{s} / \mathrm{mm}$, measured every 10 minutes, the resulting volume must be multiplied by 10 minutes by 60 seconds per minute. Dividing the result found above by $0.001 \mathrm{~m}(1 \mathrm{~mm})$ gives us the area in $m^{2}$, allowing for its comparison with the watershed's area. 
To prove that the model is viable, the reverse process was applied, where the instant unit hydrograph for the duration in excess is multiplied by an artificial precipitation (inputted into a matrix, as described earlier), as to calculate the resulting direct stream flows $\left(Q_{D}\right)$ [10]. With a first impulse of precipitation, an estimation was made to how the precipitation may fall, as well as its quantity. This was done using the typical daily precipitation distribution. The duration of the different precipitation events were compared with the time of concentration $\left(t_{c}\right)$ for the watershed, as calculated previously. It is important to assure that the precipitation durations do not exceed the time of concentration $\left(t_{c}\right)$, as this would indicate the time at which the entire watershed begins to contribute to direct runoff at its outlet. With the estimation made using the first impulse of precipitation, the direct stream flow $\left(Q_{D}\right)$ can be estimated. As more data is available for the quantity of precipitation (further precipitation impulses), its estimation using the typical daily precipitation distribution can be changed accordingly and applied to the model, allowing for a stream flow forecast in realtime. It is important to note that the precipitation inputted into the model must be the effective $\left(P_{e}\right)$ precipitation and the resulting stream flows are direct $\left(Q_{D}\right)$ flows.

\section{Results}

With the instant unit hydrographs for the duration in excess computed and verified using the methods explained in the previous sections, it was found that many indicated signs of distortion or did not correlate well with the actual size of the watershed. Therefore, one that did not present much distortion and correlated well with the size of the watershed was selected for further review. The following fig. 4 shows the selected instant unit hydrograph for the duration in excess, which was computed at the Tapijulapa stream gauge in Tabasco, Mexico.

The example selected for the instant unit hydrographs for the Tapijulapa stream gauge, as shown above in fig. 4, has proved the model viable for forecasting stream flows for a given amount of precipitation over the watershed in question.



Figure 4: Example of the instant unit hydrograph for the duration in excess. 


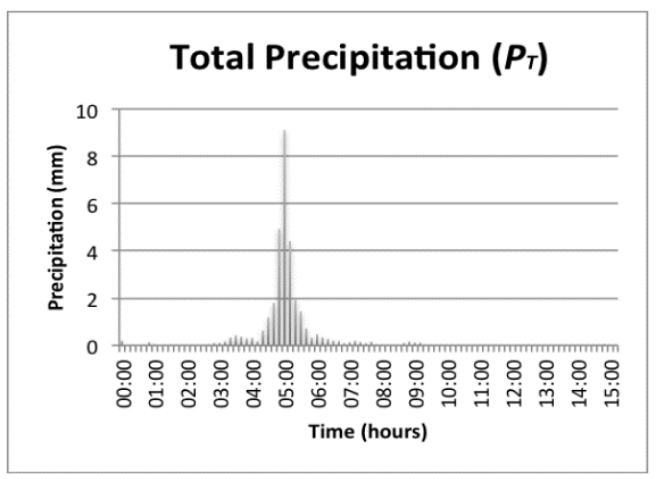

Figure 5: Total precipitation applied to the model.

The precipitation from which the runoff hydrograph will be obtained, as shown in fig. 5, was computed using a first impulse of $0.2 \mathrm{~mm}$ of precipitation, after 10 minutes. The quantity, distribution over time, and length of the precipitation was estimated using the typical daily precipitation distribution, as described in section 2.4.1. However, to be applied to the model, effective precipitation $\left(P_{e}\right)$ is needed. The mean runoff coefficient was calculated by averaging the relation between effective $\left(P_{e}\right)$ and total $\left(P_{T}\right)$ precipitation, from the historical precipitation events previously found. The mean runoff coefficient was then applied to the total precipitation $\left(P_{T}\right)$, as shown in fig. 5 , as to get its effective precipitation $\left(P_{e}\right)$. Fig. 6 shows the resulting direct stream flow $\left(Q_{D}\right)$, calculated using the instant unit hydrograph for the duration in excess presented in fig. 4 , as well as the effective precipitation $\left(P_{e}\right)$.

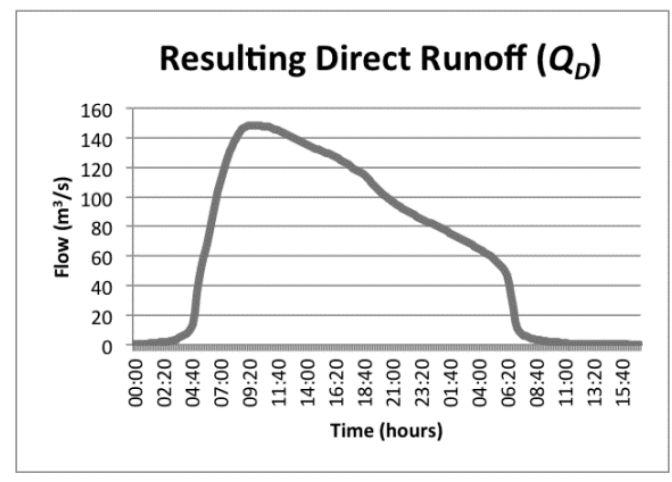

Figure 6: $\quad$ Direct runoff $\left(Q_{D}\right)$ for the precipitation applied to the model.

During the course of an actual precipitation event, precipitation impulses may be added after every 10 minutes, thus revising the precipitation forecast using the typical daily precipitation distribution. This allows for the forecast of the resulting stream flows to be revised in real-time. 


\subsection{Proposals for further research}

As oscillations were present in many of the instant unit hydrograph for the duration in excess, it would be necessary to increase the $\Delta t$ from 10 , to 20 minutes. These measures would reduce the oscillations, thus allowing for the averaging of most of the instant unit hydrographs for the duration in excess, increasing the reliability of the model. This is necessary along with further analysis of the duration in excess of precipitation, where it would be possible to simulate precipitation of different durations, allowing for a broader scope for the model's application.

As well, it is proposed that further research be conducted with regards to watersheds that are ungauged, where a synthetic unit hydrograph would be implemented into the model. This would allow for the calculation of the most common instant unit hydrograph for the duration in excess for the ungauged watershed, allowing the application of the model for stream flow forecasts in real-time.

\section{Conclusion}

It can be concluded that the model proposed for calculating the instant unit hydrograph for the duration in excess, which allows for the forecasting of stream flows in real-time, is indeed viable. However, some modifications are necessary to increase its reliability, as to be operational. Reviewing the instant unit hydrographs for the duration in excess, it is proposed that further research be done with a $\Delta t$ of 20 minutes, as to reduce the oscillations in the data. This would allow for a more comprehensive model, as there would be a greater quantity of instant unit hydrographs for the duration in excess that could be implemented into the model.

As well, the same model could easily be adapted to neighbouring subwatersheds within the larger Grijalva river watershed. This adaptation can be done with the use of precipitation as well as stream flow data from the subwatershed, thus allowing for the instant unit hydrograph for the duration in excess to be computed. All of the subwatersheds located upstream from the city of Villahermosa, Tabasco, are candidates for the application of the model, as to have a flow forecast in real-time. This would allow for an accurate flood forecast when a precipitation event reaches the area, thus allowing for a greater lead-time before a potential flood event reaches the area.

\section{References}

[1] Baltas, E., The combined use of weather radar and geographic information system techniques for flood forecasting. Advances in Geosciences, 10, pp. 117-123, 2007.

[2] Sharif, H.O., Yates, D., Roberts, R. and Mueller, C., The use of an automated nowcasting system to forecast flash floods in an urban watershed. Journal of Hydrometeorology, 7, pp. 190-202, 2006. 
[3] Hapuarachchi, H.A.P., Wang, Q.J. and Pagano, T.C., A review of advances in flash flood forecasting. Hydrological Processes, 25, pp. 2771-2784, 2011.

[4] Versini, P.-A., Use of radar rainfall estimates and forecasts to prevent flash flood in real time by using a road inundation warning system. Journal of Hydrology, 416-417, pp. 157-170, 2012.

[5] Ghile, Y., Schulze, R. and Brown, C., Evaluating the performance of ground-based and remotely sensed near real-time rainfall fields from a hydrological perspective. Hydrological Sciences Journal, 55(4), pp. 497$511,2010$.

[6] Behrangi, A., Khakbaz, B., Jaw, T.C., AghaKouchak, A., Hsu, K. and Sorooshian, S., Hydrological evaluation of satellite precipitation products over a mid-size basin. Journal of Hydrology, 397, pp. 225-237, 2011.

[7] Velasco, L., Mendoza, J., Campos, E. and Castillo, H., Analísis especial de las lluvias en la subcuenca del bajo grijalva. 2do Congreso nacional de Manejo de Cuencas Hidrográficas. Tabasco, 2011.

[8] Sharifi, S. and Hosseini, S., Methodology for identifying the best equations for estimating the time of concentration of watersheds in a particular region. Journal of Irrigation and Drainage Engineering, 137(11), pp. 712719, 2011.

[9] Universidad Nacional de Entre Ríos (UNER). Tecnología de tierras y aguas I - Escurrimiento Superficial. http://www.fca.uner.edu.ar/academicas/ deptos/catedras/riego/Archivos/Cap\%2006\%20-\%20Escurrimiento\%20 Superficial.pdf.

[10] Aparicio-Mijares, F.J., Fundamentos de hidrología de superficie, G.N. Editores Limusa: Mexico, pp. 225, 1992. 